Article

\title{
The Design of Temperature-Responsive Nanofiber Meshes for Cell Storage Applications
}

\author{
Tomohiro Maeda ${ }^{1}$, Young-Jin Kim ${ }^{1,2}$, Takao Aoyagi ${ }^{1,2}$ and Mitsuhiro Ebara 1,2,3,* \\ 1 International Center for Materials Nanoarchitectonics (WPI-MANA), National Institute for Materials \\ Science (NIMS), Tsukuba 305-0044, Japan; maeda.tomohiro@nims.go.jp (T.M.); \\ kim.youngjin@nims.go.jp (Y.-J.K.); aoyagi.takao@nims.go.jp (T.A.) \\ 2 Graduate School of Pure and Applied Sciences, University of Tsukuba, Tsukuba 305-8571, Japan \\ 3 Department of Material Science and Technology, Graduate School of Tokyo, University of Science, \\ Tokyo 278-8510, Japan \\ * Correspondence: ebara.mitsuhiro@nims.go.jp; Tel.: +81-29-860-4775; Fax: +81-29-860-4708
}

Academic Editors: Martin J. D. Clift and Stephen C. Bondy

Received: 26 January 2017; Accepted: 15 March 2017; Published: 21 March 2017

\begin{abstract}
Here we report on the fabrication and characterization of temperature-responsive electrospun nanofiber meshes using $N$-isopropylacrylamide homopolymer (PNIPAAm). The effect of molecular weight on fiber formation and their thermoresponsive shrinking/dissolution behaviors were investigated. The PNIPAAm fiber meshes showed much faster temperature-dependent shrinking or dissolution than that of its corresponding film due to its unique fibrous structure. By utilizing these quick and dynamic shrinking/dissolution properties, we successfully demonstrated the temperature-modulated "on-off" capture/release systems for macroscopic or mesoscopic-scale objects. Finally, we explored the potential application of PNIPAAm meshes for cell storage.
\end{abstract}

Keywords: temperature-responsive; nanofibers; $N$-isopropylacrylamide; cryopreservation

\section{Introduction}

Polymeric nanofibers are an exciting new class of material and have attracted great attention because of their remarkable properties, such as high specific surface area, high porosity, high molecular alignment, or nanosize effects. The increased surface area and reactivity allow them to offer potential applications for catalysis of chemical reactions, filtration, and separation technologies in medicine, and electronic devices [1-3]. Currently, there are several techniques available for the synthesis of nanofibers. Of these techniques, a process called electrospinning is the most widely studied technique and has also demonstrated the most promising results in various applications [4-8]. Electrospinning provides a relatively inexpensive and simple method of creating a variety of continuous fibers with uniform diameters from the micro- to the nanometer scale [9-11]. It is also versatile in that almost any soluble or fusible polymer can be processed into nanofibers. To date, several methods have been also developed to enhance electrospinning productivity, including gas flow-assisted electrospinning [12]. Melt blowing is a commercial one-step process for spinning polymers directly into a non-woven mesh by the drawing force of a gas flow [13]. With these additional stretching forces, small diameter fibers can be produced.

Recently, functional nanofibers have been successfully prepared from combined technology such as coaxial electrospinning, electrospinning of polymers blended with additional compounds, and electrospinning with surface modifications [14,15]. Nanofibers with multi-compositions, for example, can be prepared by electrospinning of polymers blended with nanoparticles, carbon nanotubes, ceramics, biomolecules and so on [16,17]. These functional nanofibers are promising for diverse applications such as in tissue engineering, sensors, and wound healing. Furthermore, 
functional nanofibers with core-shell structure prepared through coaxial electrospinning extend the applications of nanofibers to drug delivery [18]. Except for functional nanofibers fabricated from electrospinning with the combined installations mentioned above, nanofibers with "smart" or "stimuli-responsive" surfaces are of great interest for such applications as "on-off" switchable control of permeability, wettability, and/or swelling/deswelling behavior [19]. Because the electrospun fibers have a much larger external surface area, the meshes or mats electrospun from smart polymers display much quicker response times than the corresponding bulk materials such as hydrogels. Furthermore, the electrospun meshes can be easily manipulated as a macroscopic bulk matter that may create opportunities for profitable new uses as responsive actuators and so on.

Herein, we report on the fabrication and characterization of temperature-responsive nanofiber meshes using $\mathrm{N}$-isopropylacrylamide homopolymer (PNIPAAm) by electrospinning (Figure 1). PNIPAAm is one of the most studied temperature-responsive polymers, which undergoes a transition from a hydrophilic state to a hydrophobic state in water at $32{ }^{\circ} \mathrm{C}$ (lower critical solution temperature; LCST) [20-22]. The high solubility of PNIPAAm in water below the LCST can be attributed to the ability of the macromolecule to form H-bonds to water molecules via the amide functional groups. At the same time, the apolar isopropyl substituents of the side chains induce a considerable ordering of water molecules. This ordering causes large negative contributions to both the enthalpy and entropy of mixing. When the temperature reaches the LCST, the entropy contribution to the free energy of mixing will overcome the negative enthalpy of solution. Thus, free energy of mixing takes a positive value, and the phase separation of the polymer solution begins [23]. Although there have been several studies on electrospun PNIPAAm nanofibers, a relatively higher molecular weight or polymer concentration has been required to obtain a handy PNIPAAm mesh [24]. Another approach is an incorporation of non-soluble components or crosslinkable moieties into PNIPAAm nanofibers [25-27]. We have previously reported "on-off" capture/release of cells using PNIPAAm nanofiber meshes [28]. One of the advantages of nanofiber system is that it does not require any reaction/degradation during cell capture/release processes. For example, most problems for hydrogel-based system such as in situ gelation lie with the reagents and by-products for the crosslinking reaction, which have the potential to be toxic to cells. In this study, we examined the formation condition of electrospun meshes using a non-crosslinked PNIPAAm homopolymer with tunable fiber size without changing polymer architecture or surface chemistry. The parameters influencing the electrospinning process and morphology of the fibers are investigated. Finally, the application of PNIPAAm nanofibers toward biomedical uses such as "on-off" capture/release of cells is also explored. The mammalian cell-wrapped nanofiber mesh was subjected to cryopreservation. The cell viability tests showed that cells entrapped in the nanofiber mesh maintained higher cell viabilities than those of the conventional method.

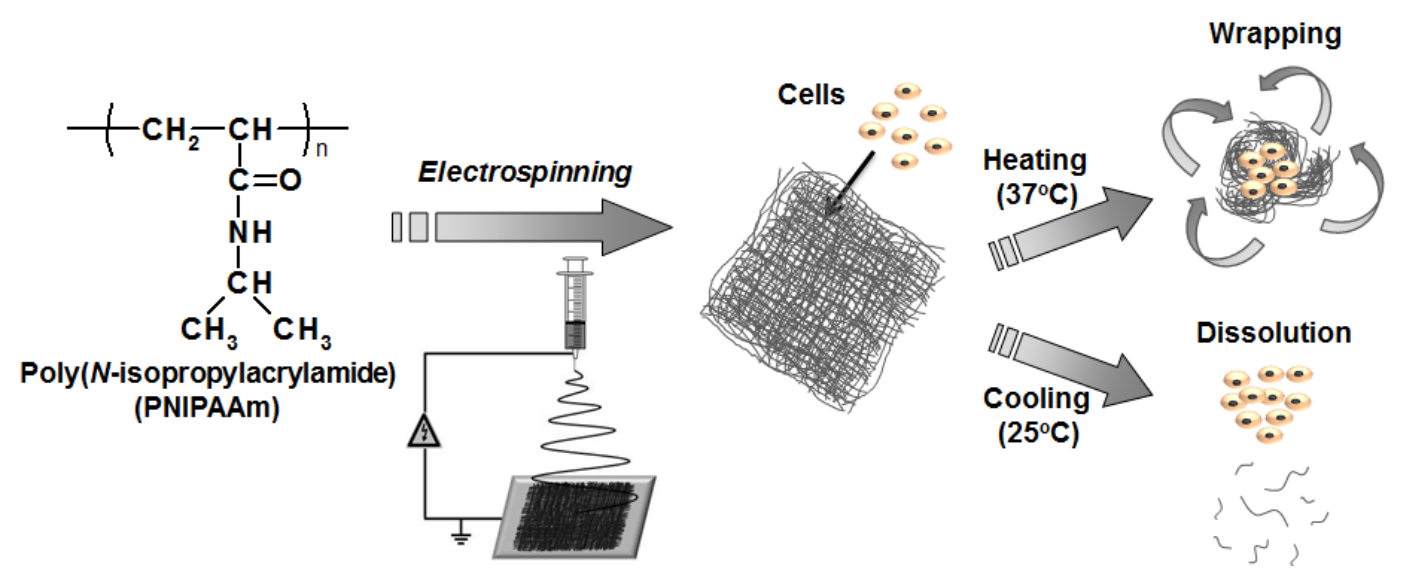

Figure 1. Schematic illustration of fabrication of PNIPAAm nanofiber mesh by electrospinning method and its potential application for cryopreservation. 


\section{Experimental Section}

\subsection{Materials}

N-Isopropylacrylamide (NIPAAm) was kindly donated by Kohjin (Tokyo, Japan) and purified using recrystallization from hexane. 2,2'-Azobis(isobutyronitrile) (AIBN, Wako Pure Chemical Industries, Tokyo, Japan) was purchased and recrystallized from ethanol. PNIPAAm with a molecular weight of 17,100, determined by gel permeation chromatography (GPC, Jasco LC-2000 Plus, JASCO, Tokyo, Japan), was prepared by free radical polymerization with AIBN as the initiator in $N, N$-dimethylformamide (DMF). PNIPAAm with molecular weights of 10,200, 231,000 and 538,800 (Polymer Source, Inc., Dorval, QC, Canada) were commercially available and used as received. All other reagents were used without further purification if not otherwise specified. The MILLI-Q Lab System supplied the ultra-pure water. The tissue culture polystylene (TCPS) dish was purchased from Iwaki Labware (Tokyo, Japan). Dulbecco's modified Eagle's medium (DMEM, high glucose) and dimethylsulfoxide (DMSO) were purchased from Sigma-Aldrich (Tokyo, Japan). Fetal bovine serum (FBS) was obtained from MP Biomedicals (Santa Ana, CA, USA). Trypsin (0.25\%)-EDTA (1 mM) solution and penicillin/streptomycin (P/S) were purchased from Nacalai Tesque (Tokyo, Japan) and Gibco (Tokyo, Japan), respectively. 3-(4,5-Dimethylthiazol-2-yl)-2,5-diphenyltetrazolium bromide (MTT) assay kit was purchased from Trevigen (TACSTM, Gaithersburg, MD, USA). CELLBANKER ${ }^{\circledR}$ was purchased from Wako (Tokyo, Japan).

\subsection{Nanofiber Fabrication}

PNIPAAm fiber meshes were prepared using an electrospinning setup (Nanon-01A, MECC Co., Ltd., Fukuoka, Japan). PNIPAAm with different molecular weights were dissolved in 1,1,1,3,3,3-hexafluoro-2-propanol (HFIP) at given concentrations (1.0, 3.0, 5.0 and $10.0 \mathrm{wt} \%$ ). The polymer solutions were placed in a plastic syringe connected with a metal needle (27G), and the solutions were supplied to the needle at a flow rate of $0.30 \mathrm{~mL} / \mathrm{h}$ by a syringe pump. An aluminum foil was used as the collector and connected to the ground. A constant positive high voltage of $10 \mathrm{kV}$ generated by a power supply was applied between the electrospun nozzle and the collector with a nozzle-to-collector distance of $15 \mathrm{~cm}$. All the experiments were carried out at $23{ }^{\circ} \mathrm{C}$ and $50 \%$ humidity [29]. Preparation conditions of the fiber meshes are summarized in Tables S1 in the Supporting Information. The obtained fiber meshes were dried in a vacuum oven at $23^{\circ} \mathrm{C}$ for $24 \mathrm{~h}$ before use. As a control, a PNIPAAm thin film with a smooth surface structure was prepared by a cast method. Briefly, PNIPAAm with a molecular weight of 17,100 was dissolved in tetrahydrofuran (THF), and the polymer solution was casted into a mold of Teflon ${ }^{\circledR}$ films (Nitto Denko Corp., Osaka, Japan). The average thickness and diameter of the cast film was $68.0 \mu \mathrm{m}$ and $2.5 \mathrm{~cm}$, respectively.

\subsection{Characterizations}

The surface morphologies of the electrospun fibers were observed using a scanning electron microscopy (SEM, JEOL JCM-5000, JEOL, Tokyo, Japan) at $10 \mathrm{kV}$ accelerating voltage. The diameter of nanofibers was measured by Image J software $(n=40)$ (National Institutes of Health, Bethesda, MD, USA). In order to evaluate the thermoresponsive behavior of the PNIPAAm fiber meshes, cold $\left(20^{\circ} \mathrm{C}\right)$ or hot $\left(40^{\circ} \mathrm{C}\right)$ water was added to the fiber meshes. The fiber meshes were cut into a circle shape with diameter of ca. $1.2 \mathrm{~cm}$. The average thicknesses of the fiber meshes were ca. 70-90 $\mu \mathrm{m}$. To estimate the shrinking kinetics of the fiber meshes above the LCST, the size of the meshes after adding hot water $\left(40^{\circ} \mathrm{C}\right)$ were measured using a CCD camera (DX-Macro750, Kyowa Optical Co., Ltd., Kanagawa, Japan) at given times. During the measurements, the fiber meshes were kept at $40{ }^{\circ} \mathrm{C}$ in water using a hot stage. The shrinking ratio was defined as a percentage of the area of the projection view of the fiber mesh at a given time after adding hot water. The dissolution behavior of the fiber meshes by adding cold water $\left(20^{\circ} \mathrm{C}\right)$ were also evaluated by taking photos of the meshes. To compare the results between fiber mesh and cast film, the same weights of samples were used $(2.5 \mathrm{mg})$. 


\subsection{Cell Culture}

A $100 \mu \mathrm{L}$ of serum free DMEM containing normal human dermal fibroblasts (NHDF) (3000 cells) was dropped on PNIPAAm nanofiber mesh with $M_{\mathrm{n}}=17,100$ followed by addition of $1 \mathrm{~mL}$ of serum free DMEM containing DMSO $(0 \%, 10 \%$, or $20 \%)$ or conventional cryopreservation solution CELLBANKER ${ }^{\circledR}$. After equilibration at $37^{\circ} \mathrm{C}$ for $5 \mathrm{~min}$, the solutions were frozen at $-80^{\circ} \mathrm{C}$ for 3 days. For thawing, samples were put into a $37^{\circ} \mathrm{C}$ incubator for $10 \mathrm{~min}$, then prewarmed serum containing medium was added to facilitate thawing. The medium was changed to remove residual DMSO at room temperature. Cell activity was assessed by MTT after thawing. After incubation, cells were treated with $500 \mu \mathrm{L}$ of DMEM containing $50 \mu \mathrm{L}$ of MTT solution for 4 hours and then incubated with $500 \mu \mathrm{L}$ of detergent reagent for $2 \mathrm{~h}$. The supernatants were placed 96-well micro plate and the absorbance at $570 \mathrm{~nm}$ was measured by ELISA micro-plate reader (BIO-RAD Laboratories) (Hercules, CA, USA). The viability was defined as the ratio of the cell numbers on day 3 to that on day 1 .

\section{Results and Discussion}

\subsection{Effects of Electrospun Conditions on the Fiber Morphology}

Although electrospinning is the simplest and easiest method that can produce a fiber of nano dimension, there are many factors that influence web characteristics $[4,11,30]$. Usually, the factors that affect electrospinning can be classified into two categories. The first factor is concerned with the rheological behavior of polymer solutions, such as the concentration, viscosity, surface tension and conductivity of the polymer solution. The second factor is concerned with the processing of the diameters of the nozzle, applied voltage, as well as tip and collector distance. When processing electrospinning, the surrounding atmospheric conditions are also an important factor. Figure 2 shows the SEM images for electrospun PNIPAAm nanofibers prepared using different conditions. The electrospun samples show the various morphologies depending on the molecular weight and polymer concentration. As for PNIPAAm with a molecular weight of 10,200, bead-like structures are formed at any concentrations because the molecular weight is relatively low to form entanglement among polymer chains. In addition, the viscosity of solution is not high enough to be sprayed continuously from a nozzle during the electrospinning process. Evaporation and the associated solidification are also important factors that affect the diameter and morphology of electrospun nanofibers. Some reports suggested that incorporation of salts or surfactants can help to produce fine nanofibers from low molecular weight polymers [31,32]. On the other hand, the fiber production from PNIPAAm with a molecular weight of 17,100 notably depended on the solution concentration. At the lowest concentration of $1.0 \mathrm{wt} \%$, bead-like structures are still observed. At higher than $5.0 \mathrm{wt} \%$, continuous and smooth fibers were successfully produced, suggesting that the degree of chain entanglement was high enough to produce continuous fibers. PNIPAAm with a higher molecular weight $(231,000$ and 538,800) was also electrospun into continuous fibers. The continuous fibers can be formed only when the polymer concentration was low. The polymer solutions were not electrospun when the polymer concentration became higher. That is, it was possible to produce continuous fibers even from the dilute solutions when a high molecular weight of PNIPAAm was used. Okuzaki et al. reported the successful preparation of PNIPAAm nanofibers with a molecular weight of 35,000 by adjusting the polymer concentration and applied voltage as $15 \mathrm{wt} \%$ and $20 \mathrm{kV}$, respectively [24]. Rockwood et al. also prepared 3D fibrous mats using PNIPAAm with a high molecular weight of 300,000 by electrospinning from different solvents [30]. Thus, it is of great importance to select appropriate polymer concentrations depending on the selected molecular weight. Figure 3 shows the diameters of fibers electrospun from PNIPAAm with different molecular weights as a function of polymer concentration. The fiber diameter was controllable in a wide diameter range (several hundreds of nanometers to several micrometers) by changing the molecular weight and the solution concentration. 


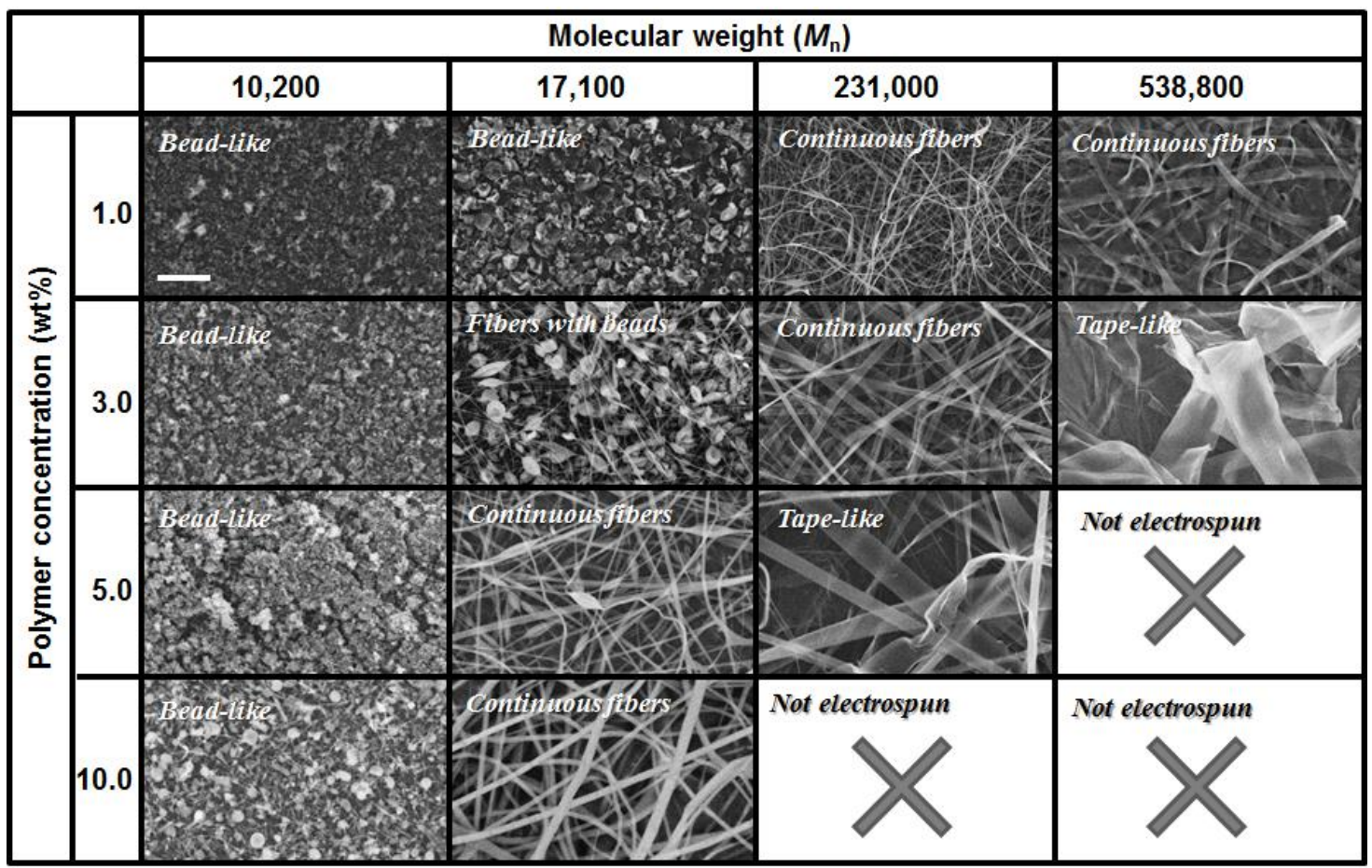

Figure 2. Effects of molecular weight and polymer concentration on the PNIPAAm fiber formation and morphologies (scale bar $10 \mu \mathrm{m}$ ).

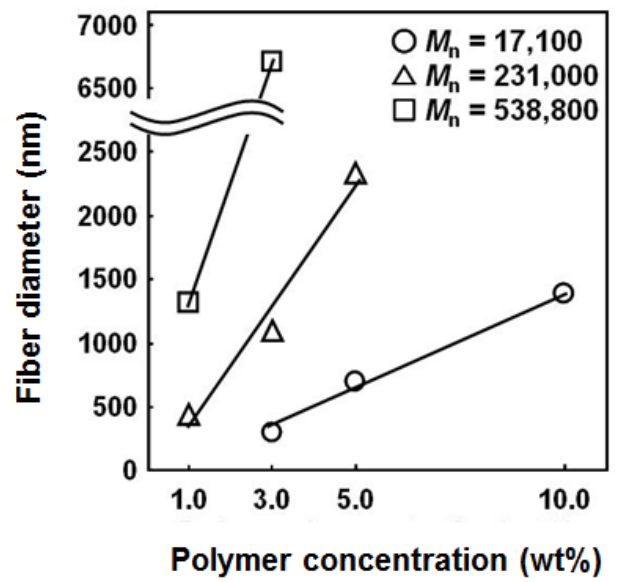

Figure 3. The effects of molecular weight and polymer concentration on the PNIPAAm fiber diameter.

\subsection{Temperature-Responsive Behavior}

The thermoresponsive behavior of the electrospun PNIPAAm fiber meshes was investigated. Figure 4a shows a photograph of the fiber mesh cut in a circle with a macroscopic size of ca. $1.2 \mathrm{~cm}$ in diameter, which was prepared from a $10.0 \mathrm{wt} \%$ solution of PNIPAAm with $M_{\mathrm{n}}=17,100$ at $10 \mathrm{kV}$. Upon adding hot water of $40^{\circ} \mathrm{C}$, the fiber mesh underwent a drastic and dynamic shrinking behavior due to a conformational change (a globule transition) of PNIPAAm above the LCST. On the other hand, a PNIPAAm cast film, which was prepared as a control and had a smooth surface with no fiber structures, hardly induced a shape change even after $24 \mathrm{~h}$ (Figure $4 \mathrm{~b}$ ). The shrinking ratios of the fiber meshes and the cast film are plotted in Figure $4 \mathrm{c}$ as a function of time after adding hot water. The fiber mesh shrank very rapidly and reached a plateau to their equilibrium state after $30 \mathrm{~s}$. In contrast, the cast film shrunk very slowly over several hours and reached only $85 \%$ shrinking ratio even after 
$24 \mathrm{~h}$. The significant difference in the shrinking behavior between the fiber meshes and the cast film was based on the fiber structural properties such as high specific surface area or porosity. It should be noted that the fiber mesh still maintained its fiber structure even after shrinking by adding hot water (see Figure S1 in the Supporting Information).

(a)

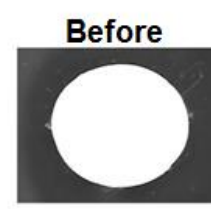

(b)

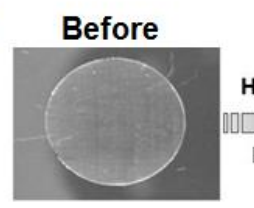

(c)

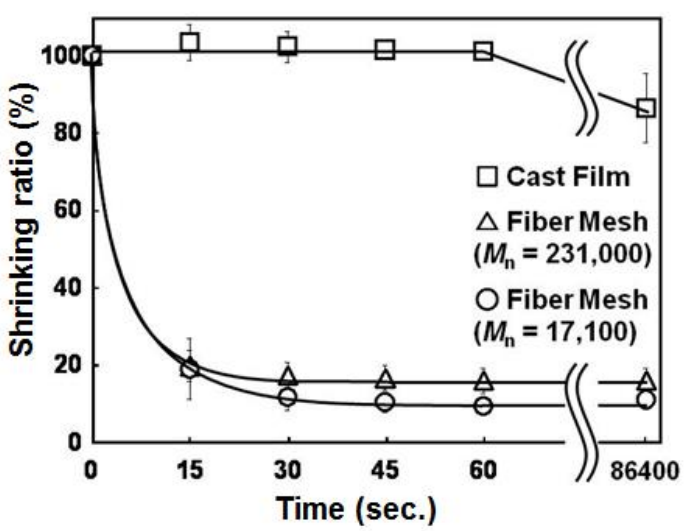

Figure 4. Time-dependent images of shrinking behavior of (a) PNIPAAm nanofiber mesh $\left(M_{\mathrm{n}}=17,100\right)$ and (b) cast film after adding hot water $\left(40^{\circ} \mathrm{C}\right)$; (c) The size changes are plotted against time.

Next, the dissolution behavior of the PNIPAAm fiber meshes was examined. Although PNIPAAm is hydrophobic and insoluble in aqueous media above the LCST, it becomes a water-soluble state below the LCST. As can be seen in Figure S2 in the Supporting Information, the fiber mesh prepared from PNIPAAm with $M_{n}=17,100$ was dissolved very swiftly within $30 \mathrm{~s}$ by adding cold water $\left(20^{\circ} \mathrm{C}\right)$. As expected, the cast film exhibited a very slow dissolution behavior for ca. $15 \mathrm{~min}$. Of particular interest is that it took $1 \mathrm{~h}$ for the fiber mesh produced from PNIPAAm with $\mathrm{Mn}=231,000$ to dissolve completely.

\subsection{Capture and Release of Cells}

To explore the potential application of PNIPAAm meshes to a novel temperature-modulated capture and release system, manipulation of macroscopic scale objects was demonstrated by utilizing their quick shrinking and dissolution responses. First, we used a glass bead of a few millimeters as a model. The bead was put on the fiber mesh and hot water was then added (Figure 5). The fiber mesh shrunk and progressively wrapped the glass bead. The glass bead was eventually captured by the mesh completely. Moreover, the captured glass bead was simply released from the fiber mesh by decreasing the temperature below the LCST since the fiber mesh was quickly dissolved at a lower temperature. These processes successfully indicated that the PNIPAAm fiber mesh can capture and release objects with macro- or mesoscopic dimensions in a precise manner based on its quick thermoresponsive behavior on a large scale. 


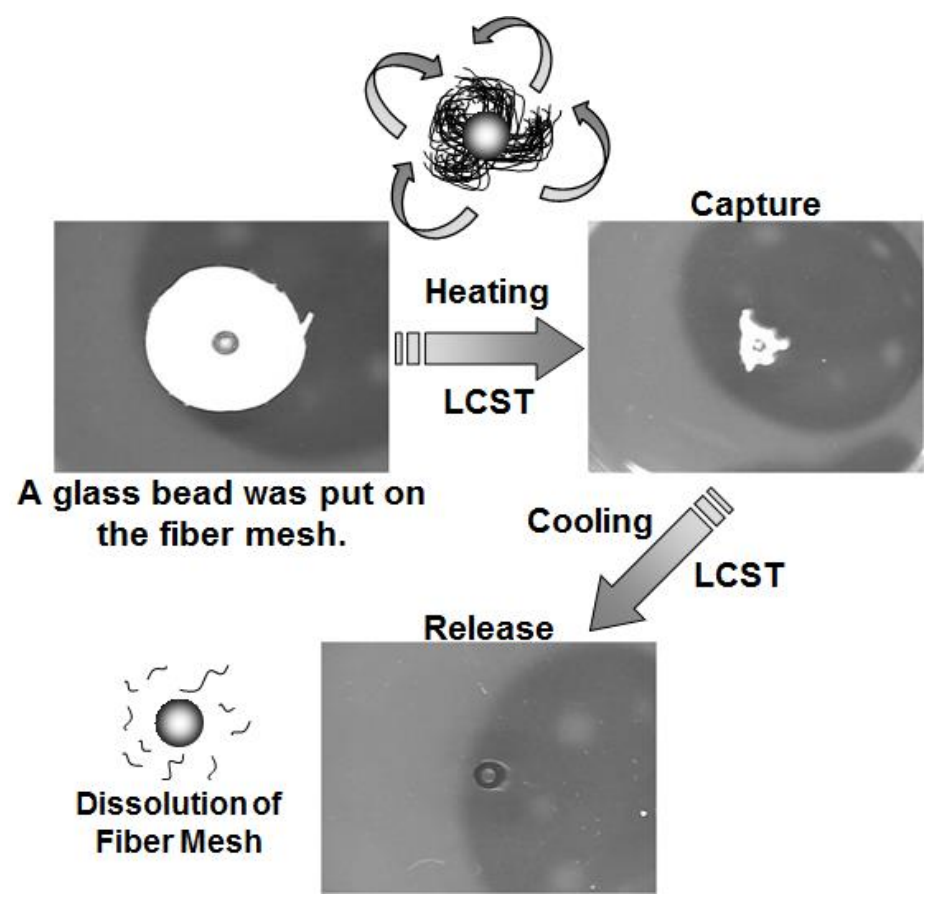

Figure 5. Temperature-modulated manipulation of a glass bead using PNIPAAm nanofiber mesh. The bead was put on the fiber mesh and hot water was added. The fiber mesh wrapped the glass bead. The captured glass bead was finally released from the fiber mesh by decreasing a temperature below the LCST.

Using this quick and dynamic response, we envision the temperature-responsive meshes in a cell storage application. As described in the Section 2.4, DMEM containing NHDF was dropped on PNIPAAm nanofiber mesh and incubated in cryoprotective DMSO solution or CELLBANKER ${ }^{\circledR}$ at $37^{\circ} \mathrm{C}$. These cryoprotective reagents are usually used to reduce the freezing point of the medium and also allow a slower cooling rate, greatly reducing the risk of ice crystal formation, which can damage cells and cause cell death [33]. The sample was then frozen at $-80^{\circ} \mathrm{C}$. After 3 days, the sample was placed into a $37^{\circ} \mathrm{C}$ incubator to facilitate thawing. The medium was changed to remove residual DMSO and dissolved PNIPAAm at room temperature. The viability of the cells was validated by MTT assay (Figure 6). As expected, the cells were dead after 3 days in liquid nitrogen without cryoprotective DMSO or CELLBANKER ${ }^{\circledR}$ (data not shown). On the other hand, cells stored with these cryoprotective reagents retained higher cell viabilities after the freezing process. The cell-containing nanofiber meshes were also subjected to the same freezing process. As shown in Figure 6, cells encapsulated in nanofiber mesh show lower viabilities than those in CELLBANKER ${ }^{\circledR}$ (open bar). However, cells in the mesh show higher cell viabilities than those without a mesh although this effect is not so significant. One of the plausible reasons is that dehydrated PNIPAAm chains suppressed the formation of large extracellular ice crystals during the freeze/thaw process. Generally speaking, when PNIPAAm is well hydrated, the hydration shell is stabilized through extensive hydrogen bonding interactions between the amide groups and water [34]. Once above the LCST, the solvent is expelled from the network accompanying the phase transition. During this process, hydrogen-bonded networks of water clusters are disrupted and broken. We postulate that the cryoprotective effect of the PNIPAAm nanofibers occurs because dehydrated PNIPAAm networks can buffer the entrapped cells from the formation of large ice crystals [35,36]. Further work is needed to determine the details of this mechanism. Nonetheless, the work described here suggests that not only is the cryopreservation of cells within the nanofiber mesh feasible, but encapsulation within the fiber mesh also provides additional protection 
during cryopreservation as compared to the unencapsulated cells. The future focus will be their potential of manipulating and delivering therapeutic purpose cells such as embryoid bodies.

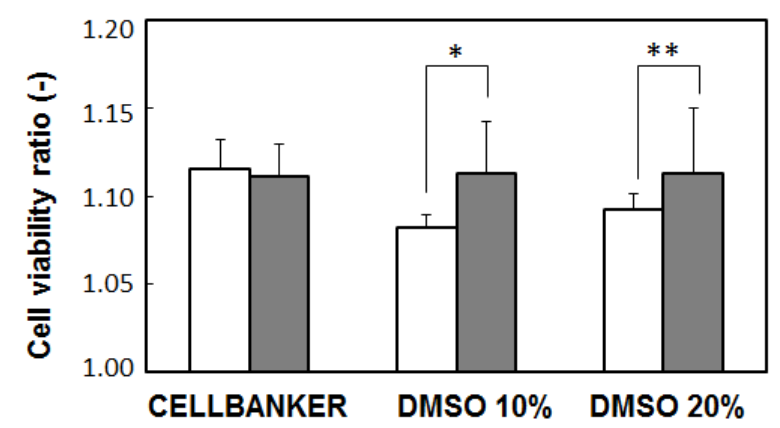

Figure 6. Viabilities of cells with (gray bar) and without (white bar) PNIPAAm nanofiber mesh in different cryoprotective reagents (CELLBANKER ${ }^{\circledR}$, DMEM with $10 \%$ or $20 \%$ DMSO). ${ }^{*} p<0.005$, ** $p<0.05$, Student's $t$-test.

\section{Conclusions}

In conclusion, temperature-responsive nanofiber meshes with a quick and dynamic response were developed by electrospinning from PNIPAAm. The fiber meshes were successfully fabricated from PNIPAAm with various molecular weights by setting electrospinning conditions properly. The molecular weight of PNIPAAm was found to be one of the most important key parameters. The obtained PNIPAAm fiber meshes exhibited temperature-responsive size/shape changes or dissolution behavior, and their response speeds were extremely high owing to the fiber structures despite their macroscopic dimensions. Furthermore, we described the cryopreservation of mammalian cells without a loss of viability during the freezing process by using a PNIPAAm mesh. Cells encapsulated in a nanofiber mesh had higher viabilities at various conditions than unencapsulated cells. The future focus will be on the effect of the storage time and mechanical properties of the mesh on cell functions such as protein expression. In addition, the details of the mechanism of the cryopreservative effect of PNIPAAm are currently being investigated.

Supplementary Materials: The following are available online at www.mdpi.com/2079-6439/5/1/13/s1.

Acknowledgments: The authors would like to express their gratitude for a Grant-in-Aid for Young Scientists (A) (25702029) from the Ministry of Education, Culture, Sports, Science and Technology (MEXT), Japan.

Author Contributions: Fiber design and fabrication was performed by T.M. The cryopreservation test was designed by Y.-J.K. The paper was written by T.M., T.A., and M.E.

Conflicts of Interest: The authors declare no conflict of interest.

\section{References and Notes}

1. Kurimoto, R.; Niiyama, E.; Ebara, M. Fibrous Materials. In Biomaterials Nanoarchitectonics; Ebara, M., Ed.; Elsevier: Oxford, UK, 2016; pp. 267-278.

2. Vasita, R.; Katti, D.S. Nanofibers and their applications in tissue engineering. Int. J. Nanomed. 2006, 1, 15-30. [CrossRef]

3. Zhou, F.-L.; Gong, R.-H. Manufacturing technologies of polymeric nanofibres and nanofibre yarns. Polym. Int. 2008, 57, 837-845. [CrossRef]

4. Greiner, A.; Wendorff, J.H. Electrospinning: A fascinating method for the preparation of ultrathin fibers. Angew.Chem. Int. Ed. 2007, 46, 5670-5703. [CrossRef] [PubMed]

5. Doshi, J.; Reneker, D.H. Electrospinning process and applications of electrospun fibers. J. Electrost. 1995, 35, 151-160. [CrossRef]

6. Reneker, D.H.; Yarin, A.L.; Fong, H.; Koombhongse, S. Bending instability of electrically charged liquid jets of polymer solutions in electrospinning. J. Appl. Phys. 2000, 87, 4531-4547. [CrossRef] 
7. Thompson, C.J.; Chase, G.G.; Yarin, A.L.; Reneker, D.H. Effects of parameters on nanofiber diameter determined from electrospinning model. Polymer 2007, 48, 6913-6922. [CrossRef]

8. Rajala, J.; Shin, H.; Lolla, D.; Chase, G. Core-Shell Electrospun Hollow Aluminum Oxide Ceramic Fibers. Fibers 2015, 3, 450-462. [CrossRef]

9. Uyar, T.; Havelund, R.; Hacaloglu, J.; Besenbachert, F.; Kingshott, P. Functional electrospun polystyrene nanofibers incorporating $\alpha-, \beta-$, and $\gamma$-cyclodextrins: compoarison of molecular filter performance. ACS Nano 2010, 4, 5121-5130. [CrossRef] [PubMed]

10. Bou, S.; Ellis, A.V.; Ebara, M. Synthetic stimuli-responsive 'smart' fibers. Curr. Opin. Biotechnol. 2016, 39, 113-119. [CrossRef] [PubMed]

11. Garrett, R.; Niiyama, E.; Kotsuchibashi, Y.; Uto, K.; Ebara, M. Biodegradable nanofiber for delivery of immunomodulating agent in the treatment of basal cell carcinoma. Fibers 2015, 3, 478-490. [CrossRef]

12. Lin, Y.; Yao, Y.; Yang, X.; Wei, N.; Li, X.; Gong, P.; Li, R.; Wu, D. Preparation of poly(ether sulfone) nanofibers by gas-jet/electrospinning. J. Appl. Polym. Sci. 2008, 107, 909-917. [CrossRef]

13. Ellison, C.J.; Phatak, A.; Giles, D.W.; Macosko, C.W.; Bates, F.S. Melt blown nanofibers: Fiber diameter distributions and onset of fiber breakup. Polymer 2007, 48, 3306-3316. [CrossRef]

14. Okada, T.; Niiyama, E.; Uto, K.; Aoyagi, T.; Ebara, M. Inactivated Sendai Virus (HVJ-E) immobilized electrospun nanofiber for cancer therapy. Materials 2016, 9, 12. [CrossRef]

15. Che, H.-L.; Lee, H.J.; Uto, K.; Ebara, M.; Kim, W.J.; Aoyagi, T.; Park, I.-K. Simultaneous drug and gene delivery from the biodegradable poly( $\varepsilon$-caprolactone) nanofibers for the treatment of liver cancer. J. Nanosci. Nanotechnol. 2015, 15, 7971-7975. [CrossRef] [PubMed]

16. Namekawa, K.; Tokoro Schreiber, M.; Aoyagi, T.; Ebara, M. Fabrication of zeolite-polymer comosite nanofibers for removal of uremic toxins from kidney failure patients. Biomater. Sci. 2014, 2, 674-679. [CrossRef]

17. Takai, R.; Kurimoto, R.; Nakagawa, Y.; Kotsuchibashi, Y.; Namekawa, K.; Ebara, M. Towards a rational design of zeolite-polymer composite nanofibers for efficient adsorption of creatinine. J. Nanomater. 2016, 2016, 5638905. [CrossRef]

18. Zhang, Y.Z.; Wang, X.; Feng, Y.; Li, J.; Lim, C.T.; Ramakrishna, S. Coaxial electrospinning of (fluorescein isothiocyanate-conjugated bovine serum albumin)-encapsulated poly(epsilon-caprolactone) nanofibers for sustained release. Biomacromolecules 2006, 7, 1049. [CrossRef] [PubMed]

19. Fu, G.D.; Xu, L.Q.; Yao, F.; Zhang, K.; Wang, X.F.; Zhu, M.F.; Nie, S.Z. Smart nanofibers from combined living radical polymerization, click chemistry, and electrospinning. ACS Appl. Mater. Interfaces 2009, 1, $239-243$. [CrossRef] [PubMed]

20. Heskins, M.; Guillet, J.E. Solution properties of poly(N-isopropylacrylamide). J. Macromol. Sci. Part A 1968, 2, 1441-1455. [CrossRef]

21. Stayton, P.S.; Shimoboji, T.; Long, C.; Chilkoti, A.; Chen, G.; Harris, J.M.; Hoffman, A.S. Control of protein-ligand recognition using a stimuli-responsive polymer. Nature 1995, 378, 472-474. [CrossRef] [PubMed]

22. Lai, J.J.; Hoffman, J.M.; Ebara, M.; Hoffman, A.S.; Estournes, C.; Wattiaux, A.; Stayton, P.S. Dual magnetic-/temperature-responsive nanoparticles for microfluidic separatrions and assays. Langmuir 2007, 23, 7385-7391. [CrossRef] [PubMed]

23. Halperin, A.; Kroger, M.; Winnik, F.M. Poly(N-isopropylacrylamide) phase diagrams: Fifty years of research. Angew. Chem. Int. Ed. 2015, 54, 15342-15367. [CrossRef] [PubMed]

24. Okuzaki, H.; Kobayashi, K.; Yan, H. Non-woven fabric of poly(N-isopropylacrylamide) nanofibers fabricated by electrospinning. Synth. Met. 2009, 159, 2273-2276. [CrossRef]

25. Okuzaki, H.; Kobayashi, K.; Yan, H. Thermo-resonsive nanofiber mats. Macromolecules 2009, 42, $5916-5918$. [CrossRef]

26. Kim, Y.-J.; Ebara, M.; Aoyagi, T. A smart hyperthermia nanofiber with switchable drug release for inducing cancer apoptosis. Adv. Funct. Mater. 2013, 23, 5753-5761. [CrossRef]

27. Kim, Y.-J.; Ebara, M.; Aoyagi, T. Temperature-responsive electrospun nanofibers for "on-off" switchable release of dextran. Sci. Technol. Adv. Mater. 2012, 12, 064203. [CrossRef] [PubMed]

28. Kim, Y.-J.; Ebara, M.; Aoyagi, T. A smart nanofiber web that captures and releases cells. Angew. Chem. Int. Ed. 2012, 51, 10537-10541. [CrossRef] [PubMed] 
29. Lolla, D.; Lolla, M.; Abutaleb, A.; Shin, H.U.; Reneker, D.H.; Chase, G.G. Fabrication, Polarization of Electrospun Polyvinylidene Fluoride Electret Fibers and Effect on Capturing Nanoscale Solid Aerosols. Materials 2016, 9, 671. [CrossRef]

30. Rockwood, D.N.; Chase, D.B.; Akins, R.E., Jr.; Rabolt, J.F. Characterization of electrospun poly(N-isopropyl acrylamide) fibers. Polymer 2008, 49, 4025-4032. [CrossRef]

31. Nartetamrongsutt, K.; Chase, G.G. The influence of salt and solvent concentrations on electrospun polyvinylpyrrolidone fiber diameters and bead formation. Polymer 2013, 54, 2166-2173. [CrossRef]

32. Zheng, J.; Zhuang, M.; Yu, Z.; Zheng, G.; Zhao, Y.; Wang, H.; Sun, D. The Effect of Surfactants on the Diameter and Morphology of Electrospun Ultrafine Nanofiber. J. Nanomater. 2014, 2014. [CrossRef]

33. Peppas, N.A.; Stauffer, S.R. Reinforced uncrosslinked poly (vinyl alcohol) gels produced by cyclic freezing-thawing processes: A short review. J. Contr. Release 1991, 16, 305-310. [CrossRef]

34. Tiktopulo, E.I.; Uversky, V.N.; Lushchik, V.B.; Klenin, S.I.; Bychkova, V.E.; Ptitsyn, O.B. “Domain” coil-globule transition in homopolymers. Macromolecules 1995, 28, 7519-7524. [CrossRef]

35. Itle, L.J.; Pishko, M.V. Cryopreservation of cell-containing poly(ethylene) glycol hydrogel microarrays. Biotechnol. Prog. 2005, 21, 1004-1007. [CrossRef] [PubMed]

36. Vrana, N.E.; O'Grady, A.; Kay, E.; Cahill, P.A.; McGuinness, G.B. Cell encapsulation within PVA-based hydrogels via freeze-thawing: A one-step scaffold formation and cell storage technique. J. Tissue Eng. Regen. Med. 2009, 3, 567-572. [CrossRef] [PubMed]

(C) 2017 by the authors. Licensee MDPI, Basel, Switzerland. This article is an open access article distributed under the terms and conditions of the Creative Commons Attribution (CC BY) license (http:/ / creativecommons.org/licenses/by/4.0/). 